\title{
Successful Percutaneous Device Closure for Giant Atrial Septal Defect with Massive Pericardial Effusion and Pulmonary Hypertension in an Elderly Patient
}

\author{
Noriko Kikuchi, MD1, Tomohiro Sakamoto, MD $^{1 *}$, Takashi Saito, MD1, Kazuhiro Nishigami, MD', \\ Teiji Akagi, MD², Takashi Honda, MD' ${ }^{1}$, Koichi Nakao, MD ${ }^{1}$ \\ ${ }^{1}$ Division of Cardiology, Saiseikai Kumamoto Hospital Cardiovascular Center, Kumamoto, Japan \\ ${ }^{2}$ Cardiac Intensive Care Unit, Okayama University Hospital, Okayama, Japan
}

\begin{abstract}
An 82-year-old man suffering from shortness of breath, leg edema, and appetite loss visited our outpatient clinic. Although he was diagnosed with atrial septal defect (ASD) requiring surgical repair $\mathbf{4 0}$ years ago, he had refused an operation at that time. Echocardiography revealed a 37-mm ASD and massive pericardial effusion. Cardiac catheterization showed significant left-to-right shunt flow with Qp/Qs of 4.6 and pulmonary artery pressure of $93 / 35 / 52 \mathrm{mmHg}$. Pulmonary vascular resistance was calculated as 8.3 Wood units. Surgical treatment was no longer indicated due to his condition, and percutaneous treatment with an Amplatzer septal occluder (ASO) was planned instead. Diuretics, a PDE3 inhibitor and nasal oxygen, were administered preoperatively for 1 month. A 38-mm ASO, the maximum occluder size available in Japan, was implanted successfully. No acute decompensation occurred after ASD closure, and the patient's symptoms improved after ASO implantation. Cardiac catheterization on postoperative day 13 revealed no evidence of residual shunt, and pulmonary artery pressure decreased to $63 / 20 / 33 \mathrm{mmHg}$. As postoperative therapy, a PDE5 inhibitor, endothelin receptor blocker, and $\mathrm{PGI}_{2}$ analog were administered for residual pulmonary hypertension. Because pericardial effusion did not disappear after pericardiocentesis, surgical pericardiostomy was performed 6 months after ASD closure, which reduced PA pressure to $34 / 16 / 24$. Appropriate
\end{abstract}

(c) 2017 Journal of Structural Heart Disease Published by Science International Corp. ISSN 2326-4004 pre- and postoperative medical therapy, device closure with an ASO, and pericardiostomy were effective in this frail patient with a giant ASD with pulmonary hypertension and massive pericardial effusion.

Copyright $\odot 2017$ Science International Corp.

Key Words:

Atrial septal defect - Pulmonary hypertension • Catheter • Intervention

\section{Introduction}

Atrial septal defect (ASD) is a common congenital heart disease in adults. The main indication for ASD closure is the presence of significant shunting as evidenced by right heart volume overload with or without symptoms [1]. Severe fixed pulmonary hypertension is considered a contraindication for surgical repair of an ASD [2]. However, development of percutaneous closure techniques and medical management may make secundum ASD closure feasible and alleviate symptoms [3].

\section{Case Presentation}

An 82-year-old Japanese man suffering from shortness of breath, leg edema, and appetite loss

*Corresponding Author:

Tomohiro Sakamoto, MD

Division of Cardiology

Saiseikai Kumamoto Hospital Cardiovascular Center

5-3-1 Chikami, Minami-ku, Kumamoto 861-4193, Japan

Tel. +81 96351 8000; Fax: +81 96351 8513; E-Mail: tomohirosakamoto@gmail.com 
visited our outpatient clinic. He was diagnosed at 43 years of age with secundum ASD requiring surgical repair but had rejected treatment at that time. At 76 years of age, he was referred from a community hospital to our institute due to shortness of breath on exertion. By this time, surgical intervention was no longer indicated because echocardiography revealed severe pulmonary hypertension (estimated right ventricular systolic pressure, $102 \mathrm{mmHg}$ ). He was treated conservatively with heart failure medications such as furosemide, digoxin, and carvedilol. However, because his symptoms had worsened considerably over the past several years, he was referred to our institute again and hospitalized while alternative treatments were considered.

Although his vital signs were stable (blood pressure, $125 / 69 \mathrm{mmHg}$; pulse rate, 69 beats per minute with irregularity), his transcutaneous oxygen saturation $\left(\mathrm{SatO}_{2}\right)$ in room air had decreased to $95 \%$. During a 6-min walk test, his SatO ${ }_{2}$ on $1 \mathrm{l} / \mathrm{min}$ of nasal oxygen declined to $88 \%$. On physical examination, his jugular veins were dilated, and facial and pretibial edema were observed. Rales were audible in both lower lung fields. His heart sounds revealed fixed splitting of the second heart sound and a systolic murmur at the second intercostal space and left-sternal border. Laboratory data showed a total bilirubin of $1.3 \mathrm{mg} / \mathrm{dl}$ and B-type natriuretic peptide of $407 \mathrm{pg} / \mathrm{ml}$. A chest X-ray revealed cardiomegaly, enlargement of the bilateral pulmonary artery, and pleural effusion (Figure 1). An electrocardiogram showed atrial fibrillation and complete right bundle branch block. Transthoracic echocardiography (TTE) revealed enlargement of the right heart, hypoplasty of the left ventricle (Figure 2A), and massive pericardial effusion (Figure 2B). In addition, there was an ostium secundum-type ASD with leftto-right shunting and moderate tricuspid regurgitation on transesophageal echocardiography (TEE) (Figure 2C). The size of the defect and the rims were also measured by TEE. His ASD showed a maximal size of $36 \times 37 \mathrm{~mm}$, and each rim was long enough for device closure (Figure 3). Cardiac catheterization revealed Qp/Qs of 4.6, pulmonary artery pressure of $93 / 35 / 52 \mathrm{mmHg}$, and pulmonary vascular resistance

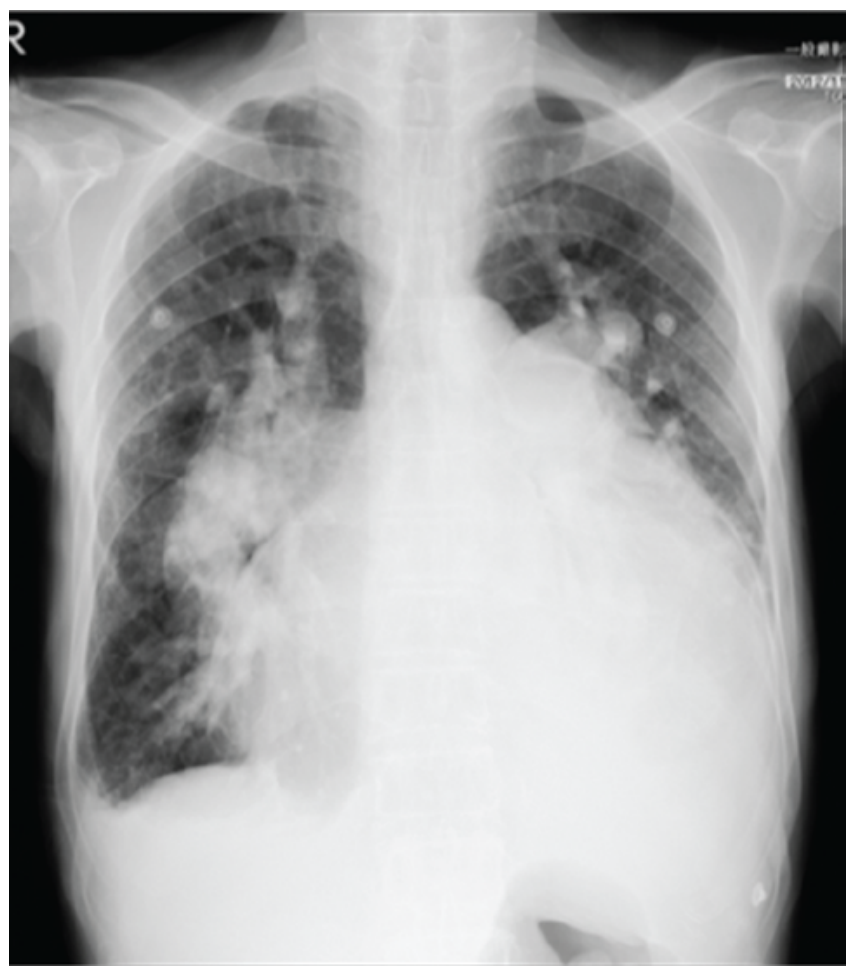

Figure 1. Chest x-ray on admission. Cardiomegaly, dilatation of the pulmonary arteries, and pleural effusion were observed.
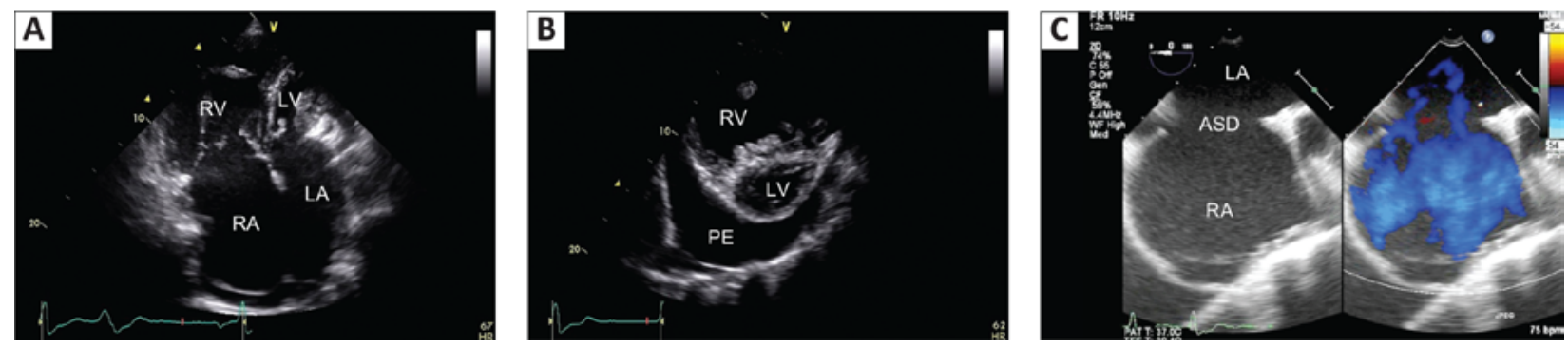

Figure 2. Panel A. Four-chamber view of transthoracic echocardiography (TTE). A large right and left atria and ASD were observed. Panel B. Short-axis view of TTE. A dilated right ventricle and hypoplastic left ventricle with massive pericardial effusion were observed. Panel C. Transesophageal echocardiography findings. A dilated right atrium and left-to-right shunt flow through the ASD were observed. $A S D=$ atrial septal defect; $L A=$ left atrium; $L V=$ left ventricle; $P E=$ pericardial effusion; $R A=$ right atrium; $R V=$ right ventricle. 


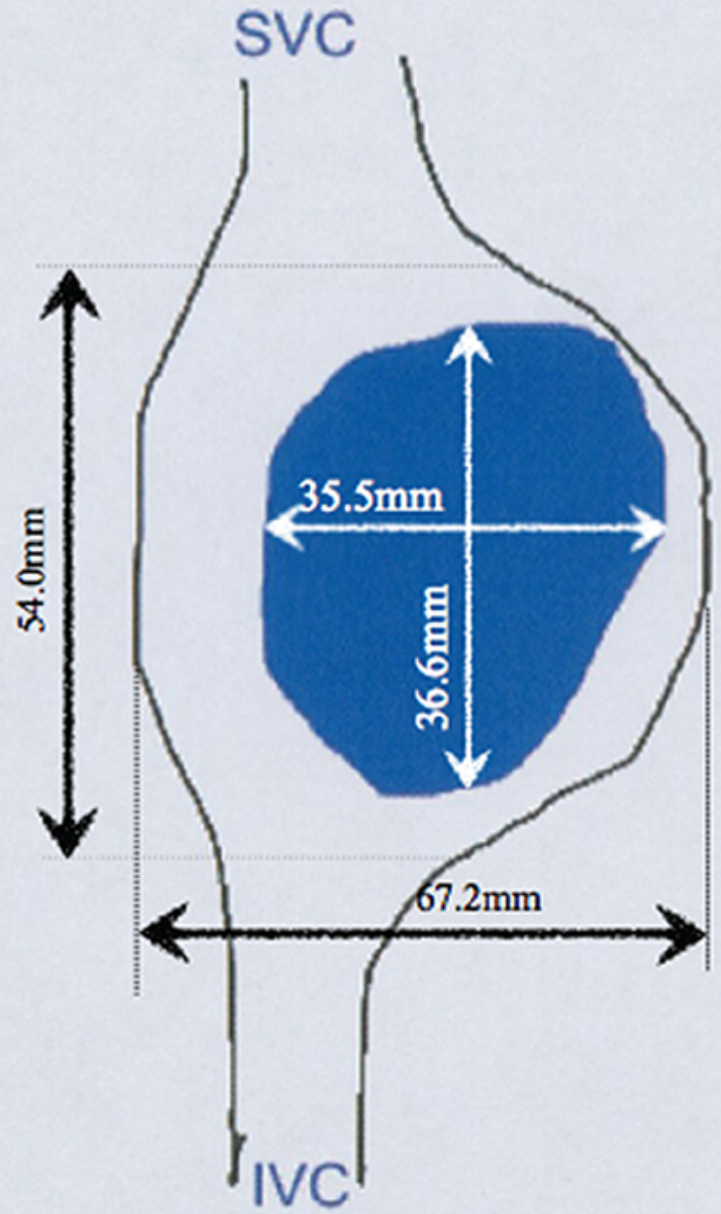

Figure 3. Transthoracic echocardiography findings of atrial septal defect (ASD). The ASD occupies large part of the atrial septum. SVC = Superior vena cava; IVC = Inferior vena cava.

(PVR) of 8.3 Wood units. His PVR index was 5.4 Woods units $\cdot \mathrm{m}^{2}$, and pulmonary-to-systemic blood pressure ratio was 0.87 .

Mainly due to his frailty, percutaneous treatment with an Amplatzer septal occluder (ASO) was planned. Two different diuretics, a PDE3 inhibitor (milrinone $0.2 \mu \mathrm{g} / \mathrm{kin} / \mathrm{min}$ ) and nasal oxygen, were administered as preoperative therapy in preparation for acute decompensation (Figure 4). After 1 month of medical treatment, we performed percutaneous device closure for atrial septal occlusion. We performed the operation while monitoring intra-cardiac pressure. When we occluded the defect with an ASO temporarily, we observed that pulmonary capillary wedge pressure and left ventricular end diastolic pressure did not rise markedly. Finally, we successfully implanted a 38-mm ASO, which was the maximum size available in Japan at the time (Figure 5). No pulmonary edema occurred after ASO implantation, and the patient's symptoms improved without oxygen administration. When cardiac catheterization was performed on postoperative day 13, there was no evidence of residual shunting, and pulmonary artery pressure had decreased to $63 / 20 / 33 \mathrm{mmHg}$. As pericardial effusion was still present after successful ASD closure, pericardiocentesis was performed, and 1,500 $\mathrm{ml}$ of fluid was removed. A PDE5 inhibitor (sildenafil $60 \mathrm{mg}$ ), endothelin receptor blocker (ambrisentan 5 $\mathrm{mg}$ ), and $\mathrm{PGI}_{2}$ analog (beraprost $120 \mu \mathrm{g}$ ) were administered to treat the remaining pulmonary hypertension. The patient was subsequently discharged from the hospital on postoperative day 41 and returned home on foot.

Three months after ASO implantation, the patient was re-hospitalized due to dyspnea on exertion because pericardial effusion appeared again, even after pericardiocentesis and intensive medical therapy (Figure 6). His pulmonary artery pressure was still high at 47/26/35 $\mathrm{mmHg}$. Therefore, surgical pericardiostomy was performed 6 months after ASD closure. Finally, his left ventricular shape became round and enlarged (Figure 7), and pulmonary artery pressure decreased to 34/16/24 (Figure 6). Finally, he was discharged again and became asymptomatic.

\section{Discussion}

We successfully treated a patient with a giant ASD along with extreme pulmonary hypertension and massive pericardial effusion percutaneously with an ASO. Therefore, this case shows that appropriate and timely pre- and postoperative medical therapy combined with ASD closure can be effective.

In patients with significant ASD, left ventricular preload is reduced and a reduction of LV volume is observed over time [4]. In these cases, closure of an ASD with a large left-to-right shunt can increase left ventricular inflow, leading to left ventricular heart failure [5]. To avoid this catastrophic condition, two diuretics and an inotropic agent were administered intravenously for 


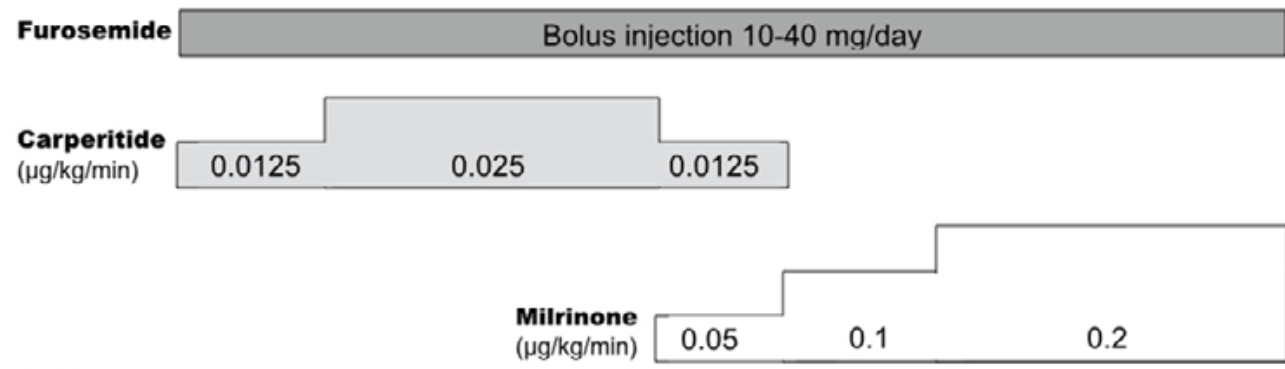

\section{Admission}

Day34

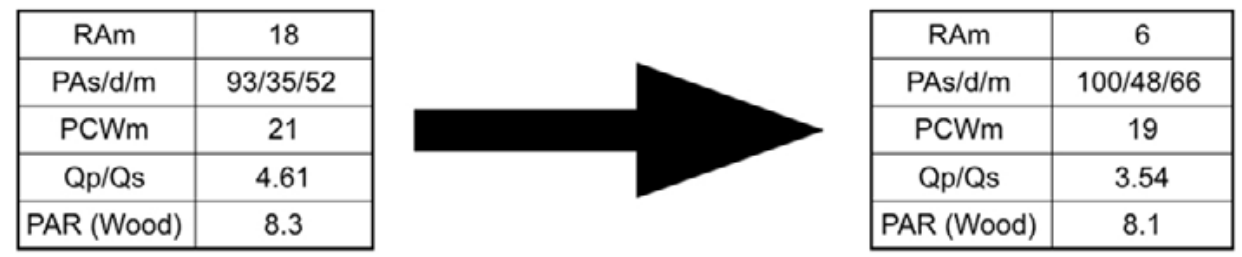

Figure 4. Preoperative medication with two diuretics and an inotropic agent. Although right atrium pressure was decreased, pulmonary artery pressure was not changed by the treatment. $\mathrm{ASO}=$ Amplatzer septal occluder; $\mathrm{m}=$ mean; $\mathrm{PA}=$ pulmonary artery; PAR = pulmonary artery resistance; PCW = pulmonary capillary wedge; Qp/Qs = pulmonary-to-systemic blood flow ratio; RA = right atrium; s/d/m: systolic/ diastolic/mean.
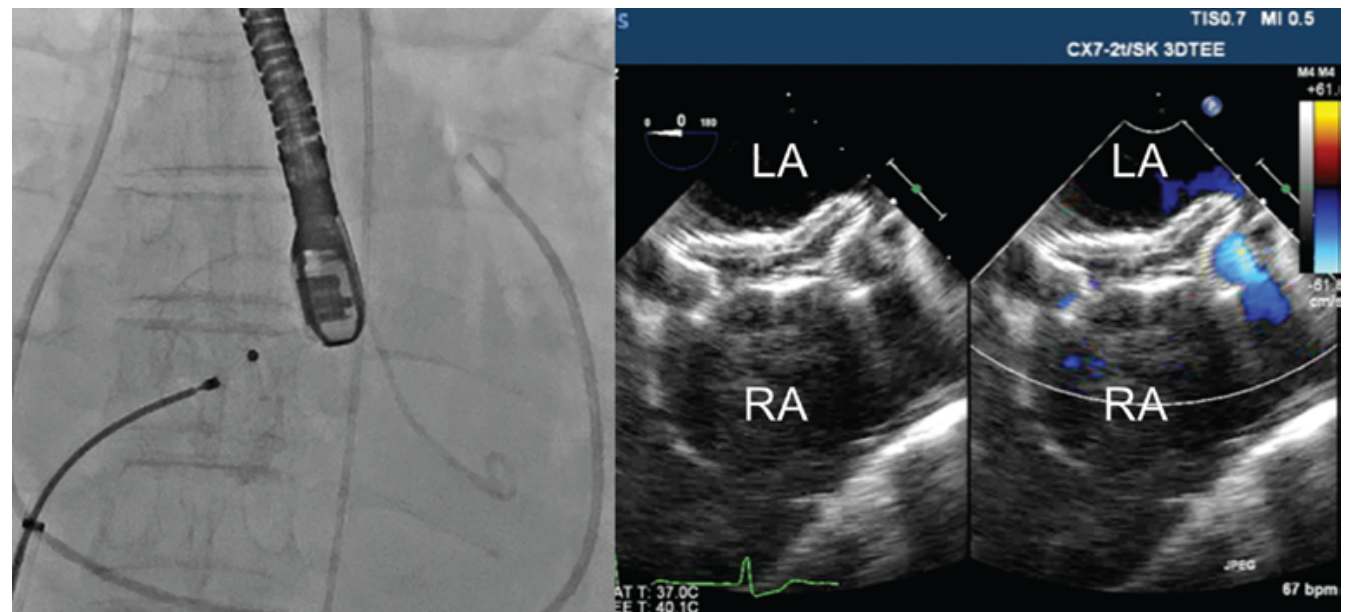

Figure 5. Angiographic (left panel) and TEE (right panel) findings during implantation of an Amplatzer septal occluder.

1 month before the operation. Although severe pulmonary hypertension was observed in this case, pulmonary artery dilators were not used before the procedure contrary to current recommendations for surgical treatment [6]. This is because a possible increase in left-toright shunt due to a reduction in pulmonary artery resistance might increase left ventricular inflow, leading to left ventricular heart failure due to masked left ventricular restriction [7] at the time of ASD closure. In this case, ASD closure with an ASO was safely performed without any hemodynamic deterioration.

As the massive left-to-right shunt was completely eliminated by ASO implantation, pulmonary artery pressure was expected to decrease after the procedure, but this did not occur. Therefore, potent pulmonary artery dilators such as a PDE5 inhibitor, endothelin receptor blocker, and $\mathrm{PGI}_{2}$ analog were started incrementally after the procedure. The present case is considered to be high risk because the PVR was greater than 5 Woods units $\mathrm{m}^{2}$, and pulmonary artery pres- 


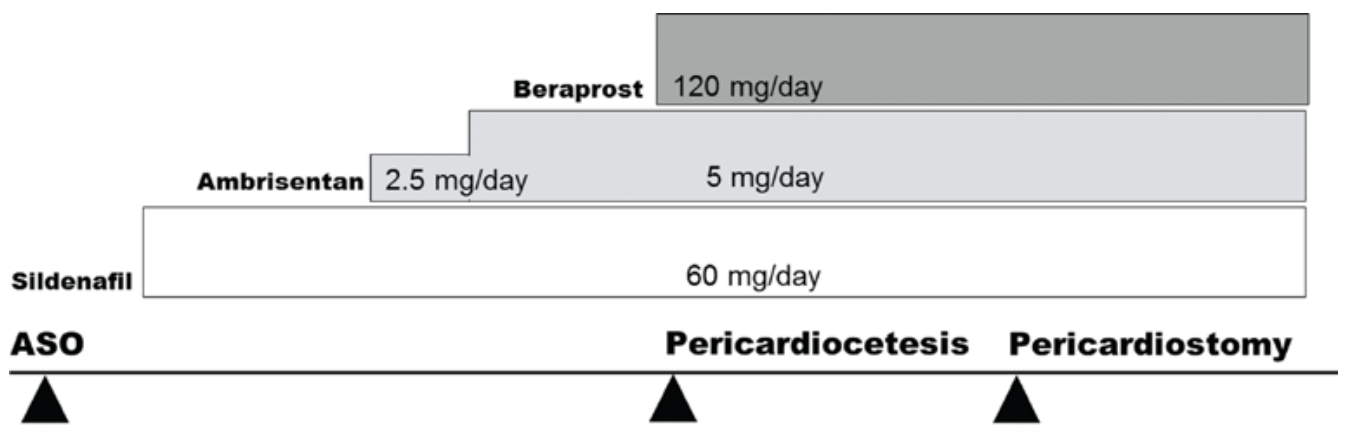

\begin{tabular}{|c|c|}
\hline $\mathrm{RAm}$ & 8 \\
\hline $\mathrm{PAs} / \mathrm{d} / \mathrm{m}$ & $63 / 20 / 33$ \\
\hline $\mathrm{PCWm}$ & 11 \\
\hline $\mathrm{BNP}$ & 326.2 \\
\hline $6 \mathrm{MD}$ & $210 \mathrm{~m}$ \\
\hline
\end{tabular}

2 weeks after ASO

\begin{tabular}{|c|c|}
\hline $\mathrm{RAm}$ & 9 \\
\hline $\mathrm{PAs} / \mathrm{d} / \mathrm{m}$ & $50 / 12 / 29$ \\
\hline $\mathrm{PCWm}$ & 14 \\
\hline $\mathrm{BNP}$ & 320 \\
\hline $6 \mathrm{MD}$ & $375 \mathrm{~m}$ \\
\hline
\end{tabular}

12 weeks after ASO

\begin{tabular}{|c|c|}
\hline $\mathrm{RAm}$ & 17 \\
\hline $\mathrm{PAs} / \mathrm{d} / \mathrm{m}$ & $47 / 26 / 35$ \\
\hline $\mathrm{PCWm}$ & 21 \\
\hline $\mathrm{BNP}$ & 231.3 \\
\hline $6 \mathrm{MD}$ & $\mathrm{n} / \mathrm{a}$ \\
\hline
\end{tabular}

20 weeks after ASO

\begin{tabular}{|c|c|}
\hline $\mathrm{RAm}$ & 6 \\
\hline $\mathrm{PAs} / \mathrm{d} / \mathrm{m}$ & $34 / 16 / 24$ \\
\hline $\mathrm{PCWm}$ & 21 \\
\hline $\mathrm{BNP}$ & 131 \\
\hline $6 \mathrm{MD}$ & $\mathrm{n} / \mathrm{a}$ \\
\hline
\end{tabular}

24 weeks after ASO

Figure 6. Medications and examinations after $\mathrm{ASO}$ implantation. $6 \mathrm{MD}=6$-min walk distance; $\mathrm{ASO}=$ Amplatzer septal occluder; $\mathrm{m}=$ mean; $\mathrm{PA}=$ pulmonary artery; $\mathrm{PCW}=$ pulmonary capillary wedge; $\mathrm{RA}=$ right atrium; s/d/m = systolic $/$ diastolic $/ \mathrm{mean}$.

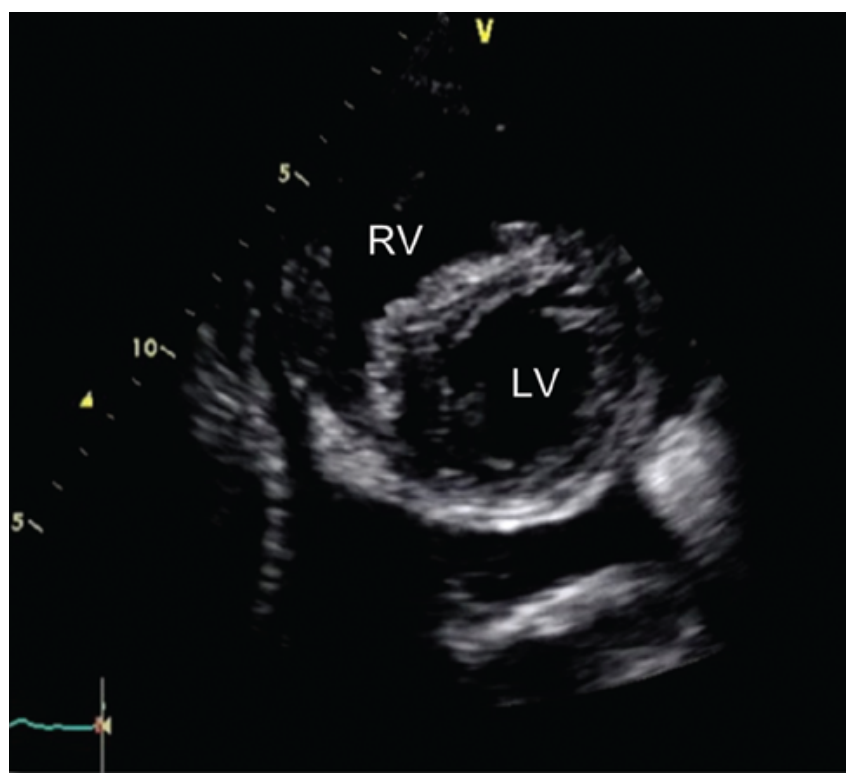

Figure 7. Short-axis view of transthoracic echocardiography after drainage of the pericardial effusion 6 months after atrial septal defect closure. The left ventricular shape became round, and the dimension of the left ventricle increased.

sure was greater than $70 \%$ of systemic pressure [8]. The pulmonary hypertension-specific medications that we administered are reportedly effective even in high-risk patients during long-term follow-up [8]. However, in our particular case, probably due to the presence of chronic massive pericardial effusion, the reduction in pulmonary arterial pressure fell short of our expectations. Because pericardiocentesis had no effect on pericardial effusion, pericardiostomy and drainage was performed according to previous reports [9]. Finally, the surgical procedure eliminated the effusion, which was followed by a decrease in pulmonary artery pressure to a nearly normal level and the disappearance of symptoms.

\section{Conclusions}

We report a case of giant ASD with massive pericardial effusion treated by ASO followed by the administration of pulmonary arterial dilators. Potent pulmonary hypertension drugs and percutaneous closure devices make high-risk ASD treatment possible, even in elderly and frail patients.

\section{Conflict of Interest}

The authors have no conflict of interest relevant to this publication.

\section{Comment on this Article or Ask a Question}




\section{References}

1. Baumgartner $\mathrm{H}$, Bonhoeffer $\mathrm{P}$, De Groot NM, de Haan F, Deanfield JE, Galie N, et al. ESC guidelines for the management of grown-up congenital heart disease (new version 2010). Eur Heart J. 2010;31:29152957. DOI: 10.1093/eurheartj/ehq249

2. Steele PM, Fuster V, Cohen M, Ritter DG, McGoon DC. Isolated atrial septal defect with pulmonary vascular obstructive disease--long-term follow-up and prediction of outcome after surgical correction. Circulation. 1987;76:1037-1042. PMID: 3664992

3. Balint $\mathrm{OH}$, Samman A, Haberer $\mathrm{K}$, Tobe $\mathrm{L}$, McLaughlin P, Siu SC, et al. Outcomes in patients with pulmonary hypertension undergoing percutaneous atrial septal defect closure. Heart. 2008;94:1189-1193. DOI: 10.1136/hrt.2006.114660

4. Ashley EA, Niebauer J. Adult congenital heart disease. In: Cardiology Explained. London: Remedica; 2004, p. 203-214.
5. Jategaonkar S, Scholtz W, Schmidt $H_{\text {, }}$ Horstkotte D. Percutaneous closure of atrial septal defects: Echocardiographic and functional results in patients older than 60 years. Circ Cardiovasc Interv. 2009;2:85-89. DOI: 10.1161/CIRCINTERVENTIONS.108.814046

6. Brunner N, de Jesus Perez VA, Richter $A$, Haddad F, Denault A, Rojas V, et al. Perioperative pharmacological management of pulmonary hypertensive crisis during congenital heart surgery. Pulm Circ. 2014;4:1024. DOI: $10.1086 / 674885$

7. Ewert $P$, Berger $F$, Nagdyman N, Kretschmar $\mathrm{O}$, Dittrich S, Abdul-Khaliq $\mathrm{H}$, et al. Masked left ventricular restriction in elderly patients with atrial septal defects: A contraindication for closure? Catheter Cardiovasc Interv. 2001;52:177-180. DOI: 10.1002/1522726X(200102) 52:2<177::AID-CCD1043> 3.0.CO;2-G
8. Akagi T. Current concept of transacted closure of atrial septal defect in adults. J Cardiol. 2015;65:17-25. DOl: 10.1016/j. jjcc.2014.09.002

9. Sagristà-Sauleda J, Mercé AS, Soler-Soler J. Diagnosis and management of pericardial effusion. World J Cardiol. 2011;3:135-143. DOI: 10.4330/wjc.v3.i5.135

Cite this article as: Kikuchi N, Sakamoto T, Saito T, Nishigami K, Akagi T, Honda T, Nakao K. Successful Percutaneous Device Closure for Giant Atrial Septal Defect with Massive Pericardial Effusion and Pulmonary Hypertension in an Elderly Patient. Journal of Structural Heart Disease 2017;32:43-48. DOI: http://dx.doi.org/10.12945/j. jshd.2017.009.16 